Check for updates

Cite this: RSC Adv., 2018, 8, 36015

\title{
The adsorption and aggregation properties of dendritic cationic tetrameric surfactants $\uparrow$
}

\author{
Yangchun Xie, ${ }^{a}$ Jie Li, (D) *a Zuofeng Li, ${ }^{\text {b }}$ Tong Sun, ${ }^{a}$ Yipeng Wang ${ }^{a}$ \\ and Guangmiao $\mathrm{Qu}^{\mathrm{a}}$
}

A series of dendritic cationic tetrameric surfactants $\left(4 C_{n}\right.$ tetraQ, $\left.n=12,14,16\right)$ were synthesized with raw materials that are commercially available. The adsorption and aggregation properties of the synthesized surfactants were studied using the Wilhelmy plate method, electrical conductivity, fluorescence spectra and dynamic light scattering techniques, and surface chemical parameters and thermodynamics parameters were obtained, respectively. These surfactants have higher surface activities than those of the corresponding monomeric and dimeric surfactants and are more prone to self-assembling in aqueous solution than adsorption at the surface. The thermodynamics parameters reflect that both adsorption and micellization processes of $4 C_{n}$ tetraQ are spontaneous, and that the micellization process is entropy-driven. Both adsorption and micellization of $4 C_{n}$ tetraQ have a tendency to occur with increasing alkyl chain length or temperature. DLS measurements show that there exist large aggregates at the concentration of 10 times the CMC.

Received 17th August 2018 Accepted 16th October 2018

DOI: $10.1039 / c 8$ ra06900j

rsc.li/rsc-advances research groups working in this area, such as Zana, ${ }^{21}$ Esumi, ${ }^{22}$ Laschewsky, $^{23}$ Menger, $^{28}$ Ikeda, $^{29}$ Yoshimura $^{30}$ and Y. L. Wang, ${ }^{34,35}$ and many fundamental studies have begun to spring up.

The oligomeric surfactants may be divided into three main types, line-type, dendritic or star-type and ring-type, according to the features of their spacer structures. Zana et al. ${ }^{21}$ reported synthesis of trimeric and tetrameric surfactants with line-type structures, and they found that the CMC values of these surfactants were lower than those of analogous monomeric or dimeric surfactants. Esumi et al. ${ }^{22}$ improved the above synthetic method and synthesized the similar trimeric surfactants by one step reaction. Laschewsky ${ }^{23}$ synthesized three series of line-type trimeric and tetrameric surfactants with rigid spacers, which were characterized of benzene ring or unsaturated double bond in the spacers. With cyanuric chloride as a core, Esumi et al. ${ }^{24}$ further synthesized the anionic ring-type trimeric surfactants $\left(3 \mathrm{C}_{n} \mathrm{NAc}-\mathrm{Tz}, n=4,10\right)$ which show unique physicochemical properties in alkali solution. Grau et al. ${ }^{25,26}$ prepared a series of sulfate-type tetrameric surfactants with multiple-ring spacers by three-step reactions from cheap tetraols. A series of ring-type surfactants were synthesized by Regen ${ }^{27}$ via the quaternization reaction, in which the starting materials could be bought commercially. Menger's group ${ }^{28}$ synthesized three series of cationic dendritic tetrameric surfactants, referred to as the multiarmed surfactants, in which the key reaction was characteristic of introducing $\alpha$-carbonyl bromide group in the spacer by acylation reaction. Ikeda ${ }^{29}$ reported the synthesis of sulfonate-type dendritic trimeric surfactants containing three hydroxyl groups. Yoshimura et al. $^{30}$ reported the synthesis of
${ }^{a}$ College of Chemistry and Chemical Engineering, Northeast Petroleum University, Daqing, 163318, P. R. China.E-mail: lijie838@nepu.edu.cn

${ }^{b}$ Natural Gas Branch Testing Center, Daqing Oil Field Co. Ltd., Daqing, 163321, China $\dagger$ Electronic supplementary information (ESI) available. See DOI: $10.1039 / \mathrm{c} 8 \mathrm{ra06900j}$ 
anionic-type trimeric surfactants $\left(3 \mathrm{C}_{n}\right.$ taAm, $\left.n=8,10,12\right)$ with tris(2-aminoethyl)amine as a spacer, in which the carbonyl groups were reduced to the methylene groups. To reduce the reaction procedure, they conducted methylation of three primary amine groups in the spacer, then carried out quaterisation and prepared the star-shaped cationic trimeric surfactants $\left(3 \mathrm{C}_{n}\right.$ trisQ, $\left.n=8,10,12,14\right) .{ }^{31}$ Uner et al. ${ }^{32}$ synthesized the star-shaped octameric surfactants by copper(I)-catalysed azidealkyne cycloaddition(CuAAC) click reaction under mild reaction conditions. Tan et $a l .{ }^{33}$ prepared the polyether-type branched tetrameric surfactant (TPE) by anion polymerization with propylene oxide (PO) and ethylene oxide (EO), and the product has good surface activities and may be used as a chemical demulsifier for crude oil emulsions. Wang and coworker ${ }^{16,17,34-37}$ synthesized a series of oligomeric surfactants and studied their physicochemical properties in the solution, in which the star-shaped hexameric quaternary ammonium surfactant (PAHB) is a potential condensing agent for gene transfection. ${ }^{19}$

In previous work, the dendritic cationic tetrameric surfactant with alkyl chain of $12\left(4 \mathrm{C}_{12}\right.$ tetraQ) was synthesized by a simple two-step reaction using commercially available materials. $^{38}$ This tetrameric surfactant shows good surface activity, emulsifying ability, foam performance, and application prospects. To more understand adsorption and self-assembly behaviors of the cationic tetrameric surfactants with dendritic structures, the paper synthesized this type of surfactants $\left(4 \mathrm{C}_{n^{-}}\right.$ tetraQ, $n=12,14,16)$. Their physicochemical properties were studied by Wilhelmy plate method, electrical conductivity, fluorescence spectra and dynamic light scattering technique.

\section{Experimental}

\subsection{Materials}

Ethanol and acetone were purchased from Tianjin Kermel Chemical Reagents Development Centre. Pyrene was purchased from Sigma-Aldrich and recrystallized thrice before use.

\subsection{Synthesis}

The synthesis route of dendritic cationic tetrameric surfactants with different alkyl chains $\left(4 \mathrm{C}_{n}\right.$ tetraQ, $\left.n=12,14,16\right)$ was shown in Fig. 1. The detailed synthesis procedure was listed in the literature. ${ }^{38}$ Fourier transform infrared (FT-IR) spectra were obtained using a Perkin Elmer Spectrum One (U.S.) by KBr disk method. ${ }^{1} \mathrm{H}$ NMR measurements were carried out using a Bruker Avance III 400 spectrometer (Switzerland) operating at $400 \mathrm{MHz}$, in which deuteroxide $\left(\mathrm{D}_{2} \mathrm{O}\right)$ was used as a solvent. The elemental analysis measurements were conducted using a Vario EL-III CHNOS instrument (Germany).

\subsection{Surface tension measurements}

Surface tension measurements were carried out using the QBZY-2 automatic tensionmeter (Shanghai Fangrui Instrument Co., Ltd., China) by Wilhelmy plate method. The surfactant solution was aged for 12 hours before measurement. The average of three surface tension measurements of pure water was $71.80 \pm 0.04 \mathrm{mN} \mathrm{m}^{-1}$ at $25{ }^{\circ} \mathrm{C}$.

\subsection{Conductivity measurements}

Conductivity measurements of the surfactant solution were conducted by a DDS-11A digital conductimeter (Shanghai Kangyi Instruments Co., Ltd, China). The variations of conductivity $v s$. concentration of surfactants at different temperature were seen in Fig. 3, and the results were given in Table 2 .

\subsection{Steady-state fluorescence measurements}

Steady-state fluorescence measurements were conducted by a PerkinElmer LS-55 spectrofluorometer (PerkinElmer Co., Ltd., U.K.) at $25{ }^{\circ} \mathrm{C}$. All the measurement parameters were given as follows: the excitation wave length, $335 \mathrm{~nm}$; the slit widths of the excitation and emission: $4.5,2.5 \mathrm{~nm}$, respectively; the range of the emission spectra: 345-460 $\mathrm{nm}$; the scan speed: 20 $\mathrm{nm} \min ^{-1}$; the concentration of fluorescence probe (pyrene): 1 $\times 10^{-7} \mathrm{~mol} \mathrm{~L}^{-1}$. The intensity ratio $\left(I_{1} / I_{3}\right)$ between the first peak (around $372 \mathrm{~nm}$ ) and the third peak (around $384 \mathrm{~nm}$ ) may be used to determine the CMC of surfactants and estimate the micellar micropolarity sensed by pyrene.

\subsection{Dynamic light scattering measurements}

Dynamic light scattering (DLS) measurements were performed to investigate the size distribution of surfactants using a Malvern Instruments Zetasizer Nano-ZS90 (Malvern Instrument Ltd, English) at $25{ }^{\circ} \mathrm{C}$. All the experiments were made thrice at a scattering angle of $90^{\circ}$ and the wavelength of $633 \mathrm{~nm}$. The sample aqueous solution was filtered by a filter of $0.22 \mu \mathrm{m}$ (mixed cellulose ester).

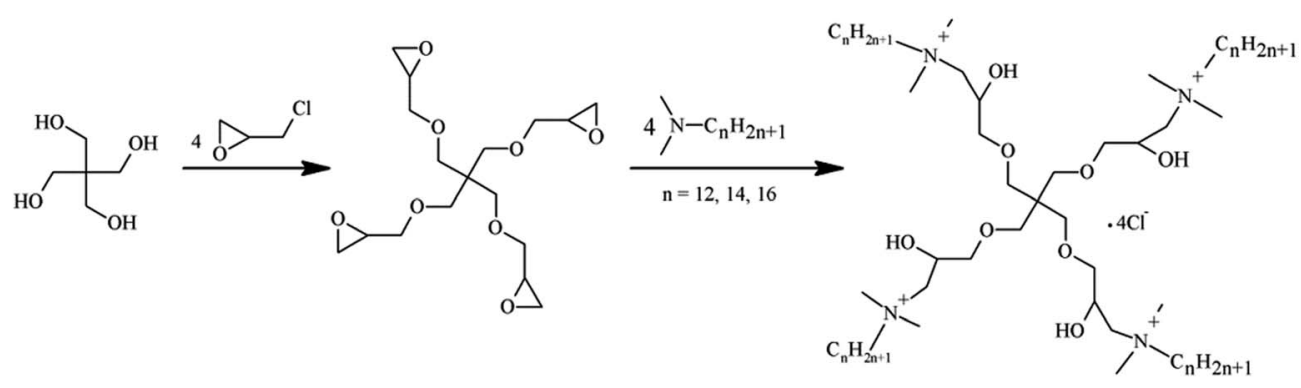

Fig. 1 The synthesis route of the dendritic tetrameric surfactants $\left(4 C_{n}\right.$ tetraQ, $\left.n=12,14,16\right)$. 


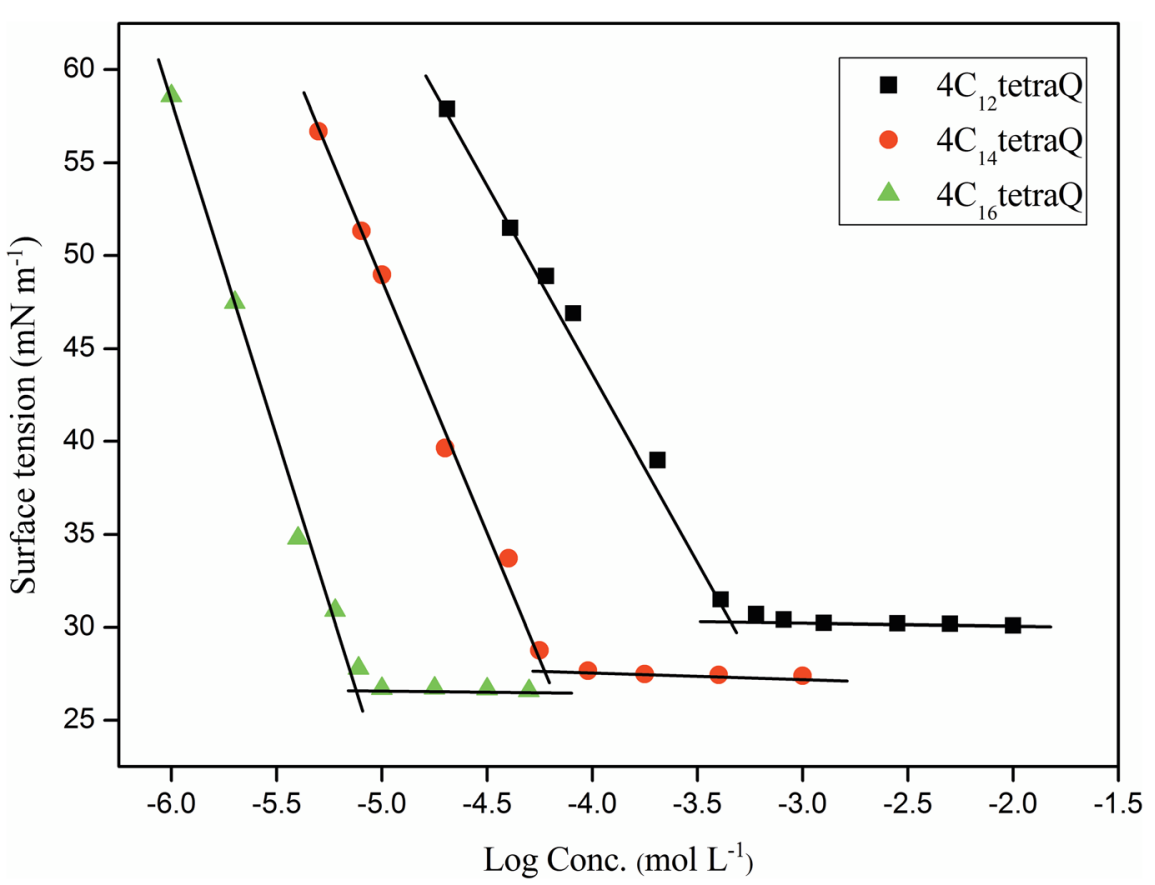

Fig. 2 The curves of surface tension vs. log concentration of $4 C_{n}$ tetraQ $(n=12,14,16)$ at $25^{\circ} \mathrm{C}$.

\section{Results and discussion}

\subsection{Characterization}

The chemical structures of the synthesized tetrameric surfactants were confirmed by FTIR, ${ }^{1} \mathrm{H}$ NMR and elemental analysis, and FTIR and ${ }^{1} \mathrm{H}$ NMR spectra were provided in the ESI. $\dagger$

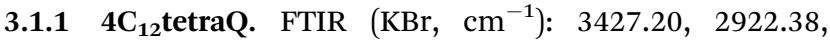
2852.51, 1472.43, 1462.41, 1083.75, 1048.67, 718.84. ${ }^{1} \mathrm{H}$ NMR (400 MHz, $\left.\mathrm{D}_{2} \mathrm{O}, \mathrm{ppm}\right) \delta: 0.82\left(\mathrm{t}, 12 \mathrm{H}, \mathrm{CH}_{3}-\mathrm{CH}_{2}\right), 1.24(\mathrm{~m}, 64 \mathrm{H}$, $\left.\mathrm{CH}_{3}-\left(\mathrm{CH}_{2}\right)_{8}\right), 1.31\left(\mathrm{~m}, 8 \mathrm{H}, \mathrm{CH}_{3}-\left(\mathrm{CH}_{2}\right)_{8}-\mathrm{CH}_{2}\right), 1.67\left(\mathrm{~m}, 8 \mathrm{H}, \mathrm{CH}_{2}-\right.$ $\mathrm{CH}_{2}-\mathrm{N}^{+}$), $2.84\left(\mathrm{~s}, 24 \mathrm{H}, \mathrm{CH}_{3}-\mathrm{N}^{+}-\mathrm{CH}_{3}\right), 2.94-3.75$ (m, 32H, $\mathrm{CH}_{2}-$ $\mathrm{N}^{+}-\mathrm{CH}_{2}, \mathrm{CH}_{2}-\mathrm{O}-\mathrm{CH}_{2}$ ), 3.97 (s, 4H, HO-CH-CH ). Anal. calc. for $\mathrm{C}_{73} \mathrm{H}_{156} \mathrm{O}_{8} \mathrm{~N}_{4} \mathrm{Cl}_{4}$ (\%), C 64.48, $\mathrm{H}$ 11.56, $\mathrm{N} \mathrm{4.12;} \mathrm{found} \mathrm{( \% ):} \mathrm{C}$ 64.07, H 11.61, N 4.08.

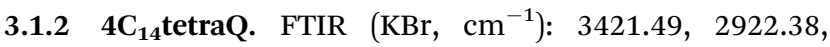
2851.10, 1472.07, 1463.75, 1106.62, 1052.25, 719.93. ${ }^{1} \mathrm{H}$ NMR (400 MHz, $\left.\mathrm{D}_{2} \mathrm{O}, \mathrm{ppm}\right) \delta: 0.89\left(\mathrm{t}, 12 \mathrm{H}, \mathrm{CH}_{3}-\mathrm{CH}_{2}\right), 1.27(\mathrm{~m}, 80 \mathrm{H}$, $\left.\mathrm{CH}_{3}-\left(\mathrm{CH}_{2}\right)_{10}\right), 1.32\left(\mathrm{~m}, 8 \mathrm{H}, \mathrm{CH}_{3}-\left(\mathrm{CH}_{2}\right)_{8}-\mathrm{CH}_{2}\right), 1.87(\mathrm{~m}, 8 \mathrm{H}$, $\left.\mathrm{CH}_{2}-\mathrm{CH}_{2}-\mathrm{N}^{+}\right), 2.81\left(\mathrm{~s}, 24 \mathrm{H}, \mathrm{CH}_{3}-\mathrm{N}^{+}-\mathrm{CH}_{3}\right), 2.94-3.75(\mathrm{~m}, 32 \mathrm{H}$, $\mathrm{CH}_{2}-\mathrm{N}^{+}-\mathrm{CH}_{2}, \mathrm{CH}_{2}-\mathrm{O}-\mathrm{CH}_{2}$ ), 4.02 (s, 4H, HO-CH-CH ). Anal. calc. for $\mathrm{C}_{81} \mathrm{H}_{172} \mathrm{O}_{8} \mathrm{~N}_{4} \mathrm{Cl}_{4}(\%), \mathrm{C} 66.09, \mathrm{H}$ 11.78, $\mathrm{N} \mathrm{3.81;} \mathrm{found}$ (\%): C 65.66, H 11.82, N 3.77.

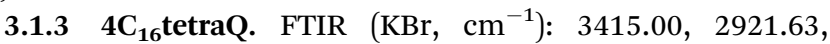
$2852.45,1472.25,1462.36,1101.45,1052.71,719.34 .{ }^{1} \mathrm{H}$ NMR (400 MHz, $\left.\mathrm{D}_{2} \mathrm{O}, \mathrm{ppm}\right) \delta: 0.88\left(\mathrm{t}, 12 \mathrm{H}, \mathrm{CH}_{3}-\mathrm{CH}_{2}\right), 1.25(\mathrm{~m}, 96 \mathrm{H}$, $\left.\mathrm{CH}_{3}-\left(\mathrm{CH}_{2}\right)_{12}\right), 1.31\left(\mathrm{~m}, 8 \mathrm{H}, \mathrm{CH}_{3}-\left(\mathrm{CH}_{2}\right)_{8}-\mathrm{CH}_{2}\right), 1.89(\mathrm{~m}, 8 \mathrm{H}$, $\left.\mathrm{CH}_{2}-\mathrm{CH}_{2}-\mathrm{N}^{+}\right), 2.84\left(\mathrm{~s}, 24 \mathrm{H}, \mathrm{CH}_{3}-\mathrm{N}^{+}-\mathrm{CH}_{3}\right), 2.94-3.75(\mathrm{~m}, 32 \mathrm{H}$, $\mathrm{CH}_{2}-\mathrm{N}^{+}-\mathrm{CH}_{2}, \mathrm{CH}_{2}-\mathrm{O}-\mathrm{CH}_{2}$ ), 4.01 (s, 4H, HO-CH-CH ). Anal.

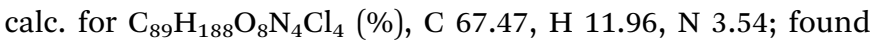
(\%): C 67.02, H 12.01, N 3.50.

\subsection{Surface activity}

3.2.1 Critical micelle concentration. The curves of surface tension $v s$. logarithm concentration of $4 \mathrm{C}_{n}$ tetraQ at $25{ }^{\circ} \mathrm{C}$ were plotted in Fig. 2, and analyzed data were summarized in Table 1. The surface tension of $4 \mathrm{C}_{n}$ tetraQ solution initially decreases with increasing concentration, and then reaches a plateau. The concentration at the break point in the surface tension plot is taken as the CMC of the surfactant, and the plateau represents the formation of aggregates. The CMC of $4 \mathrm{C}_{n}$ tetraQ $(n=12,14$, 16) gradually decreases with the increasing length of the hydrophobic chain from 12 to $16\left(0.39,0.0501\right.$ and $0.0063 \mathrm{mmol} \mathrm{L}^{-1}$, respectively). This indicates that there is a direct relationship between CMC and alkyl chain length of dendritic oligomeric surfactants, that is, the longer the alkyl chain is, the lower it is.

It is obviously that the CMC of $4 C_{n}$ tetraQ decreases by 1-3 order of magnitude than those of analogous monomeric surfactant (for instance, DTAB) and dimeric surfactant (Gemini, 12-2-12), and their values are close to the values of the cationic trimeric surfactants having the line or star type structure (12-212-2-12 and $3 \mathrm{C}_{12}$ trisQ, respectively). This may be due to strong hydrophobic interaction among four hydrophobic chains in the same molecule, which also demonstrates that the synthesized surfactants have an excellent ability of the micelle formation in comparison with the monomeric or dimeric surfactants. These results are accordance with those obtained from star-like cationic trimeric surfactants reported by Liu et al. ${ }^{39}$

The minimum surface area $\left(A_{\min }\right)$ and the surface excess concentration $\left(\Gamma_{\max }\right)$ could be calculated by the Gibbs adsorption equation as follows, ${ }^{40}$ and the calculated results were given in Table 1. 

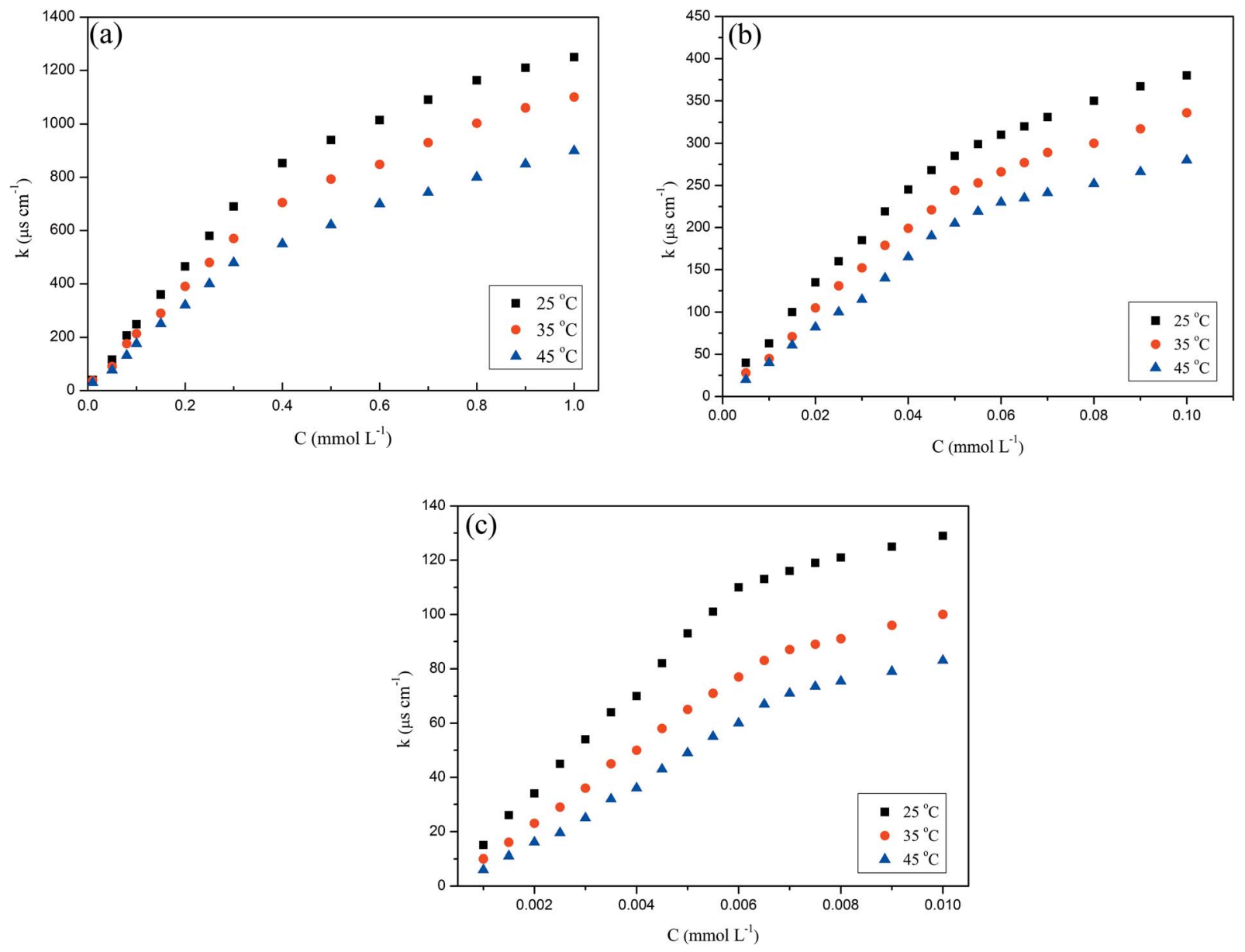

Fig. 3 Variations of electrical conductivity $(\kappa)$ vs. concentration of $4 C_{n}$ tetraQ at different temperature: (a), $4 C_{12}$ tetraQ; (b), $4 C_{14}$ tetraQ; (c), $4 \mathrm{C}_{16}$ tetraQ.

$$
\begin{gathered}
\Gamma_{\max }=-\frac{1}{2.303 n R T}\left(\frac{\partial_{\gamma}}{\partial_{\log C}}\right)_{T} \\
A_{\min }=\frac{1}{N_{\mathrm{A}} \Gamma_{\max }}
\end{gathered}
$$

where, $R=8.314 \mathrm{~J} \mathrm{~mol}^{-1} \mathrm{~K}^{-1}, T=298.15 \mathrm{~K}, N_{\mathrm{A}}=6.02 \times 10^{23}$ $\mathrm{mol}^{-1} . C$ is the surfactant concentration $\left(\mathrm{mol} \mathrm{L}^{-1}\right) . \partial_{\gamma} / \partial_{\log C}$ is the slope of surface tension curves at surfactant concentration below the CMC. $n$ is the number of species at the air/solution interface. ${ }^{21}$ It is well known that the value of $n$ is 2 for a univalent surfactant in calculating $\Gamma$, but for an ionic dimeric surfactant, there are different views $(n=2$ or $n=3) .{ }^{41-44}$ The same problem arises for ionic tetrameric surfactants consisting of a tetravalent surfactant ion and four univalent counterions. ${ }^{25}$ Thus, the values of $\Gamma_{\max }$ in the paper were calculated by $n=4$ or $n=5$, respectively. The $n$ value ( $n=4$ or 5 ) has effect on calculating $\Gamma_{\max }$ and $A_{\min }$, while it has not bearing on the way $\Gamma_{\max }$ and $A_{\min }$ vary with the alkyl carbon number. Thus, the

\begin{tabular}{|c|c|c|c|c|c|c|c|c|c|}
\hline \multirow[b]{2}{*}{ Compounds } & \multirow[b]{2}{*}{$\mathrm{CMC}\left(\mathrm{mmol} \mathrm{L}^{-1}\right)$} & \multirow[b]{2}{*}{$\gamma_{\mathrm{CMC}}\left(\mathrm{mN} \mathrm{m}^{-1}\right)$} & \multicolumn{2}{|c|}{$\begin{array}{l}\Gamma_{\max } / 10^{-6} \\
\left(\mathrm{~mol} \mathrm{~m}{ }^{-2}\right)\end{array}$} & \multicolumn{2}{|c|}{$A_{\min }\left(\mathrm{nm}^{2}\right)$} & \multirow[b]{2}{*}{$\Pi_{\mathrm{CMC}}\left(\mathrm{mN} \mathrm{m}^{-1}\right)$} & \multirow[b]{2}{*}{$p C_{20}$} & \multirow[b]{2}{*}{$\mathrm{CMC} / C_{20}$} \\
\hline & & & $n=4$ & $n=5$ & $n=4$ & $n=5$ & & & \\
\hline $4 \mathrm{C}_{12}$ tetraQ & 0.39 & 30.29 & 1.09 & 0.88 & 1.52 & 1.89 & 41.51 & 4.40 & 9.79 \\
\hline $4 \mathrm{C}_{14}$ tetraQ & 0.0501 & 27.68 & 1.24 & 0.99 & 1.34 & 1.67 & 44.12 & 5.11 & 6.45 \\
\hline $4 \mathrm{C}_{16}$ tetraQ & 0.0063 & 26.76 & 1.73 & 1.39 & 0.96 & 1.20 & 45.40 & 5.78 & 3.80 \\
\hline $12-2-12-2-12^{c}$ & $0.08^{c}$ & $36.4^{c}$ & $1.29^{c}$ & & $1.28^{c}$ & & - & - & - \\
\hline $3 \mathrm{C}_{12} \operatorname{tris}^{c}$ & $0.139^{c}$ & $32.3^{c}$ & $0.82^{c}$ & & $2.03^{c}$ & & - & - & - \\
\hline
\end{tabular}

Table 1 Surface active parameters of $4 C_{n}$ tetraQ and other different type of surfactants at $25^{\circ} \mathrm{C}$

${ }^{a}$ Values are taken from ref. 51. ${ }^{b}$ Values are taken from ref. $52 .{ }^{c}$ Values are taken from ref. 30. 
conclusions inferred from these variations do not be affected by the change of the $n$ value.

As shown in Table 1, the increase of $\Gamma_{\max }$ and the decrease of $A_{\min }$ of these tetrameric surfactants are with an increase of length of alkyl chain from 12 to 16 . This shows that the tetrameric surfactants with longer alkyl chains have higher packing densities at the air/solution interface, which may be due to that the longer alkyl tails are more prone to stretch $^{\mathbf{4 5}}$ and have stronger hydrophobic interaction between each other. ${ }^{46}$

3.2.2 Effectiveness and efficiency. Adsorption efficiency $\left(p C_{20}\right)$ and effectiveness of surface tension reduction $\left(\Pi_{\mathrm{CMC}}\right)$ can be calculated by the eqn (3) and (4). ${ }^{47} p C_{20}$ may show adsorption efficiency of surfactant molecules at the air/solution interface. ${ }^{48}$ $\Pi_{\mathrm{CMC}}$ is also known as the surface pressure at the CMC, and represents the maximum reduction of surface tension of water resulted from adsorption of surfactant molecules at the air/ solution interface. ${ }^{49}$

$$
\begin{gathered}
p C_{20}=-\log C_{20} \\
\Pi_{\mathrm{CMC}}=\gamma_{0}-\gamma_{\mathrm{CMC}}
\end{gathered}
$$

where, $C_{20}$ is the logarithm concentration of surfactants required to reduce surface tension of pure water by $20 \mathrm{mN} \mathrm{m}^{-1}$, $\gamma_{0}$ and $\gamma_{\mathrm{CMC}}$ are surface tension of pure water and surfactant solution at the CMC, respectively.

As seen in Table 1 , the values of $p C_{20}$ and $\Pi_{\mathrm{CMC}}$ of $4 \mathrm{C}_{n}$ tetraQ increase with increasing length of hydrophobic chain. The $p C_{20}$ values of tetrameric surfactants are two or more higher than that of DTAB, indicating that $4 \mathrm{C}_{n}$ tetraQ molecules are more prone to adsorption at the air/solution interface than those of the analogue monomeric surfactant. The ratio of $\mathrm{CMC} / C_{20}$ can evaluate the structural factors in the process of adsorption or formation of aggregates. ${ }^{5}$ The higher the $\mathrm{CMC} / C_{20}$ is, the greater the tendency of surfactant molecules adsorbing at the interface rather than forming aggregates is. ${ }^{50}$ Thus, these dendritic tetrameric surfactants are more prone to self-assemble in aqueous solution rather than adsorb at the surface.

\subsection{Thermodynamics parameters}

Electrical conductivity of surfactant solution may be used to investigate thermodynamic properties of micellization. As shown in Fig. 3, the pre-micellar slope $\left(S_{1}=\mathrm{d} \kappa / \mathrm{d} C\right)$ and the post-micellar slope $\left(S_{2}=\mathrm{d} \kappa / \mathrm{d} C\right)$ are obtained from the curves of electrical conductivity $(\kappa)$ vs. $4 \mathrm{C}_{n}$ tetraQ concentration. The concentration of the break point between the two straight lines in the plots may be regarded as the CMC. As can be given in Table 2, the CMC values increase with increasing temperature. These values are slightly larger than those from surface tension measurements, which is in accordance with the results obtained from other cationic oligomeric surfactants. ${ }^{53,54}$

Micelle ionization degree $(\alpha)$ may be represented by the ratio between the pre-micellar slope and the post-micellar slope $(\alpha=$ $\left.S_{2} / S_{1}\right)$, and the degree of counterion binding $(\beta)$ is calculated by the equation $(\beta=1-\alpha) .^{55} \beta$ may represent the number of counterions contained in the Stern layer in order to balance the electrostatic force that can inhibit the formation of micelles. ${ }^{56}$

The $\beta$ values increase with the increasing of alkyl tail length, which is due to that the increase of charge densities of aggregate surface is with the increasing of alkyl tail length. This means that the polar head groups of surfactant molecules with longer chains in the aggregates can bind relatively more counterions. ${ }^{57,58}$

Thermodynamic parameters at 25, 35 and $45{ }^{\circ} \mathrm{C}$ were calculated by the following equation, ${ }^{45,59,60}$ and the results were seen in Table 2 .

$$
\begin{gathered}
\Delta G_{\mathrm{mic}}^{\mathrm{o}}=R T(0.25+\beta) \ln X_{\mathrm{CMS}} \\
\Delta G_{\mathrm{ads}}^{\mathrm{o}}=\Delta G_{\mathrm{mic}}^{\mathrm{o}}-6.023 \times 10^{-2}\left(\frac{\prod_{\mathrm{CMC}}}{\Gamma_{\max }}\right) \\
\Delta H_{\mathrm{mic}}^{\mathrm{o}}=\frac{-R T^{2}(0.25+\beta) \alpha_{\ln \chi_{\mathrm{CMC}}}}{\alpha_{T}} \\
\Delta S_{\mathrm{mic}}^{\mathrm{o}}=\frac{\Delta H_{\mathrm{mic}}^{\mathrm{o}}-\Delta G_{\mathrm{mic}}^{\mathrm{o}}}{T}
\end{gathered}
$$

where, $\Delta G_{\text {mic }}^{\mathrm{o}}$ and $\Delta G_{\text {ads }}^{\mathrm{o}}$ are the standard Gibbs free energy changes of micellization and adsorption, respectively. $\Delta H_{\text {mic }}^{\mathrm{o}}$ is the standard enthalpy change of micellization process. $\Delta S_{\text {mic }}^{\mathrm{o}}$ is the standard entropy of micelle formation. $\Pi_{\mathrm{CMC}}$ is surface

\begin{tabular}{|c|c|c|c|c|c|c|c|c|c|}
\hline \multirow[b]{2}{*}{ Compounds } & \multirow[b]{2}{*}{$T\left({ }^{\circ} \mathrm{C}\right)$} & \multirow{2}{*}{$\begin{array}{l}\text { CMC } \\
\left(\mathrm{mmol} \mathrm{L}^{-1}\right)\end{array}$} & \multirow[b]{2}{*}{$\beta$} & \multirow{2}{*}{$\begin{array}{l}\Delta G_{\mathrm{mic}}^{\mathrm{o}} \\
\left(\mathrm{kJ} \mathrm{mol}^{-1}\right)\end{array}$} & \multirow{2}{*}{$\begin{array}{l}\Delta H_{\mathrm{mic}}^{\mathrm{o}} \\
\left(\mathrm{kJ} \mathrm{mol}^{-1}\right)\end{array}$} & \multirow{2}{*}{$\begin{array}{l}\Delta S_{\text {mic }}^{\mathrm{o}} \\
\left(\mathrm{kJ} \mathrm{mol} \mathrm{mol}^{-1} \mathrm{~K}^{-1}\right)\end{array}$} & \multirow{2}{*}{ 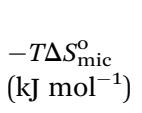 } & \multicolumn{2}{|c|}{$\Delta G_{\mathrm{ads}}^{\mathrm{o}}\left(\mathrm{kJ} \mathrm{mol}^{-1}\right)$} \\
\hline & & & & & & & & $n=4$ & $n=5$ \\
\hline \multirow[t]{3}{*}{$4 \mathrm{C}_{12}$ tetraQ } & 25 & 0.412 & 0.66 & -26.64 & -1.48 & 0.0844 & -25.16 & -30.45 & -31.36 \\
\hline & 35 & 0.422 & 0.65 & -27.17 & -1.538 & 0.0831 & -25.63 & & \\
\hline & 45 & 0.430 & 0.63 & -27.38 & -1.63 & 0.0809 & -25.75 & & \\
\hline \multirow[t]{3}{*}{$4 \mathrm{C}_{14}$ tetraQ } & 25 & 0.0484 & 0.69 & -32.16 & -1.17 & 0.1039 & -30.98 & -35.72 & -36.62 \\
\hline & 35 & 0.0490 & 0.66 & -32.50 & -1.22 & 0.1015 & -31.28 & & \\
\hline & 45 & 0.0501 & 0.64 & -32.76 & -1.27 & 0.099 & -31.49 & & \\
\hline \multirow[t]{3}{*}{$4 \mathrm{C}_{16}$ tetraQ } & 25 & 0.0063 & 0.71 & -38.05 & -4.24 & 0.1134 & -33.81 & -40.68 & -41.32 \\
\hline & 35 & 0.0067 & 0.69 & -38.36 & -4.44 & 0.11 & -33.92 & & \\
\hline & 45 & 0.0070 & 0.67 & -38.65 & -4.63 & 0.1069 & -34.02 & & \\
\hline
\end{tabular}
pressure at the CMC. $X_{\mathrm{CMC}}$ is mole fraction of the surfactant at the CMC. $\beta$ is the degree of counterion bound to micelles.

As shown in Table 2, the changes of the free energy of adsorption $\left(\Delta G_{\mathrm{ads}}^{\mathrm{o}}\right)$ and micellization $\left(\Delta G_{\mathrm{mic}}^{\mathrm{o}}\right)$ are negative,

Table 2 Thermodynamic parameters in the micellization and adsorption processes for $4 C_{n}$ tetraQ 
which means that both processes are spontaneous. ${ }^{61}$ Therefore, the adsorption at the air/solution interface or aggregation in the bulk solution is more favorable than distribution of surfactant molecules in water. The values of $\Delta G_{\text {ads }}^{\text {o }}$ of $4 \mathrm{C}_{n}$ tetraQ are bigger than those of $\Delta G_{\text {mic }}^{\mathrm{o}}$, showing that adsorption process favorably occurs until all the air/solution interface is occupied, and then surfactant molecules begin to aggregate and form micelles in the bulk solution..$^{53,62}$ The values of $\Delta G_{\text {ads }}^{\mathrm{o}}$ and $\Delta G_{\text {mic }}^{\mathrm{o}}$ in the negative direction increase with the increase of the hydrophobic chain or solution temperature. The increase of the hydrophobic chain length of the surfactant make its hydrophobicity become strong, which can destroy the structure of water and increase free energy of the system, resulting in the migration of surfactant molecules to the air/solution interface and/or the formation of micelles in bulk solution. This behavior can make energy of the surfactant system decrease, and thus the values of $\Delta G_{\text {ads }}^{\mathrm{o}}$ and $\Delta G_{\text {mic }}^{\mathrm{o}}$ are more negative. The temperature rise of the surfactant system can make the decrease of hydration around hydrophilic groups, which results in the increase of the system energy, so the surfactant molecules are more favorable to adsorption in the interface and formation of micelle in order to decrease energy of the surfactant system. ${ }^{63}$

The positive sign of $\Delta S_{\text {mic }}^{\mathrm{o}}$ suggests that entropy change is favorable to aggregate in clusters for surfactant molecules in bulk solution. ${ }^{64}$ The decrease of $\Delta S_{\text {mic }}^{\mathrm{o}}$ with the temperature rise is due to that iceberg structure around hydrophilic groups diminishes in size or becomes easier to curl. The negative sign of $\Delta H_{\mathrm{mic}}^{\mathrm{o}}$ shows that the micellization process is exothermic. ${ }^{53}$ As shown in Table 2, the values of $\Delta H_{\text {mic }}^{\mathrm{o}}$ are far lower than those of $-T \Delta S_{\text {mic }}^{\mathrm{o}}$, showing that micellization processes of these surfactant molecules are entropy-driven. ${ }^{53,65}$

\subsection{Microenvironment}

As is well known that the useful information on the micellization of surfactants is obtained from the fluorescence measurements, in which pyrene as a fluorescence probe can be solubilized in the palisade layer of aggregates when the surfactant concentrations are above the CMC. ${ }^{66}$ The intensity ratio between the first and third vibrational peaks $\left(I_{1} / I_{3}\right)$ in the fluorescence spectrum is a sensitive parameter characterizing the polarity of the probe's microenvironment. ${ }^{67}$ The ratio of $I_{1} / I_{3}$ decrease when pyrene is moved from a polar region to a nonpolar region (aggregates). ${ }^{39}$

Fig. 4 shows variations of the pyrene polarity ratio $\left(I_{1} / I_{3}\right) v s$. surfactant concentration at $25{ }^{\circ} \mathrm{C}$. The value of $I_{1} / I_{3}$ changes slightly with the increase of initial surfactant concentration, showing that pyrene has no interaction with surfactants at the beginning. ${ }^{64,68}$ Then, the $I_{1} / I_{3}$ value decreases abruptly with the increase of the surfactant concentration, which suggests that a spot of aggregates begin to form, and that pyrene is solubilized in the inner hydrophobic region of aggregates. ${ }^{69}$ Thereafter, the ratio of $I_{1} / I_{3}$ is almost constant because the micellar microenvironment in the surfactant system is no change. The minimum ratio of $I_{1} / I_{3}$ decreases with the increment of the hydrophobic chain length, implying that hydrophobic interaction among longer alkyl tails makes the palisade layer arrange more compact and result in a reduction for polarity. ${ }^{64,70}$ The plots in Fig. 4 were sigmoidal (Boltzmann type) in nature, and thus the CMC may be obtained in terms of the procedure proposed by Zana et al. ${ }^{71-74}$ The CMC values for $4 \mathrm{C}_{12}$ tetraQ, $4 \mathrm{C}_{14}$ tetraQ and $4 \mathrm{C}_{16}$ tetraQ were found to be $0.16,0.048$, and $0.0043 \mathrm{mmol} \mathrm{L}^{-1}$, which are approximately in agreement with

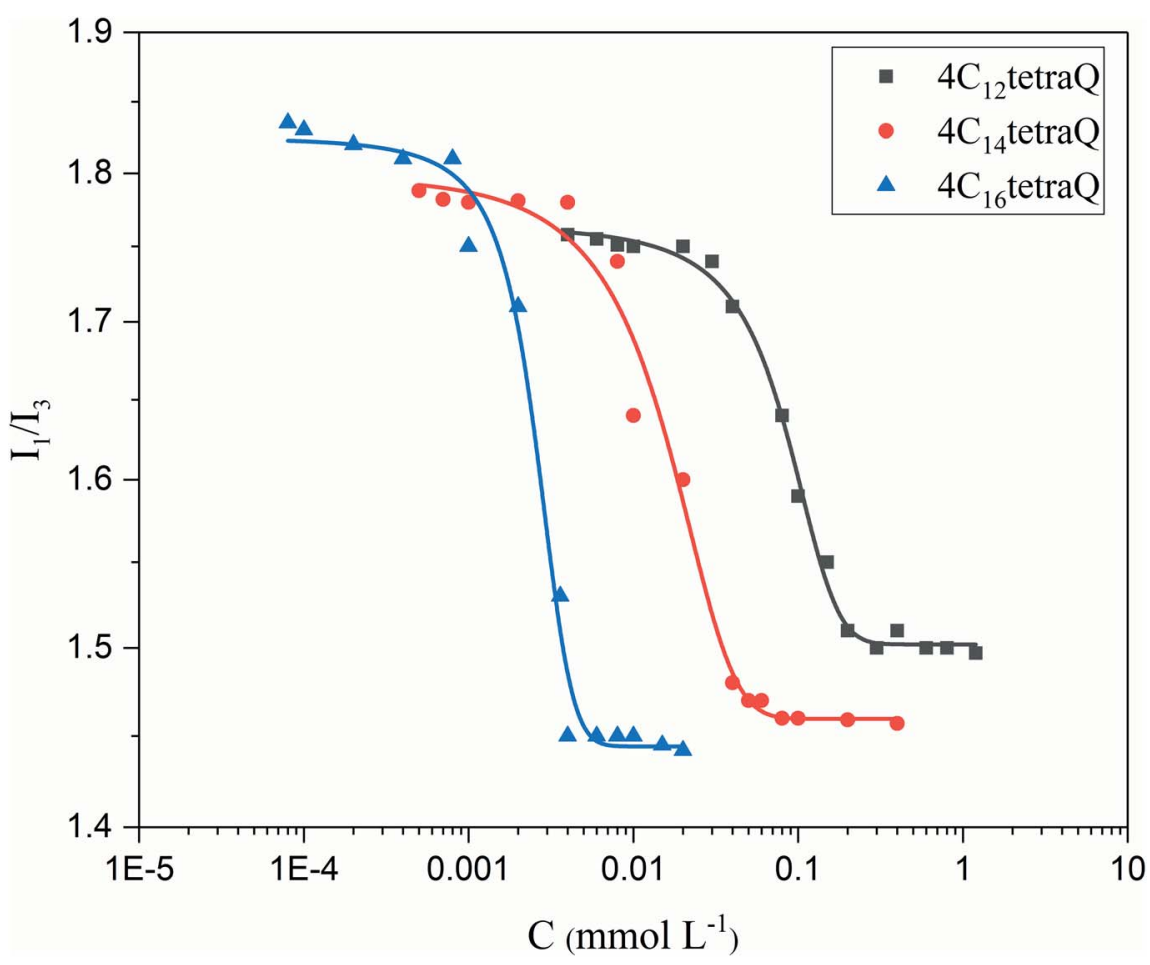

Fig. 4 Variation of the pyrene intensity ratio $\left(I_{1} / /_{3}\right)$ vs. surfactant concentration at $25^{\circ} \mathrm{C}$. 
Table 3 Packing parameter $(P)$ and other physicochemical parameters for $4 C_{n}$ tetraQ

\begin{tabular}{|c|c|c|c|c|c|c|c|c|}
\hline \multirow[b]{2}{*}{ Surfactants } & \multirow[b]{2}{*}{$V_{\text {hydrophobic }}\left(\mathrm{nm}^{3}\right)$} & \multirow[b]{2}{*}{$l_{0}(\mathrm{~nm})$} & \multicolumn{2}{|l|}{$R_{\text {range }}$} & \multicolumn{2}{|l|}{$P$} & \multicolumn{2}{|c|}{$R(\mathrm{~nm})$} \\
\hline & & & $n=4$ & $n=5$ & $n=4$ & $n=5$ & $n=4$ & $n=5$ \\
\hline $4 \mathrm{C}_{12}$ tetraQ & 1.40 & 1.67 & $0.92-1.84$ & $1.48-2.22$ & 0.55 & 0.44 & 3.68 & 2.96 \\
\hline $4 \mathrm{C}_{14}$ tetraQ & 1.62 & 1.92 & $1.21-2.41$ & $0.97-1.94$ & 0.63 & 0.50 & 4.84 & 3.88 \\
\hline $4 \mathrm{C}_{16}$ tetraQ & 1.83 & 2.17 & $1.91-3.81$ & $1.53-3.05$ & 0.89 & 0.70 & 7.63 & 6.10 \\
\hline
\end{tabular}

the results obtained from electrical conductivities and surface tension measurements.

\subsection{Aggregate behavior}

The critical packing parameter $(P)$ may be used to estimate the geometric construction of surfactant aggregates and calculated by the following equations. ${ }^{75-77}$

$$
\begin{gathered}
P=\frac{V_{\text {hydrophobic }}}{\left(a_{0} \times l_{0}\right)} \\
V=(27.4+26.9 m) \times 10^{-3} \mathrm{~nm}^{3} \\
l_{0}=(0.15+0.1265 m) \mathrm{nm} \\
R=\frac{4 V}{A_{\text {min }}}
\end{gathered}
$$

where, $a_{0}$ is the average parking area of the polar head group in a surfactant molecule. $V_{\text {hydrophobic }}$ and $l_{0}$ are the volume and length of an alkyl chain, respectively. And $m$ is the number of carbon atoms in an alkyl chain.

According to the theory of critical packing parameter, for spherical aggregates the $p$ value is less than 0.333 ; for non- spherical aggregates, $0.33 \leq P<0.50$; for vesicles or bilayers, $1 / 2<P \leq 1 .{ }^{75,76}$ As seen in the Table 3 , the $P$ values of these three surfactants are mostly above 0.5 , suggesting that they can aggregate and may be possible to form vesicles structure. To further investigate aggregation behavior of these tetrameric surfactants at the concentration of 10 times of CMC, their size distributions were studied by DLS, and the measurement results were shown in Fig. 5. As shown in Fig. 5, two apparent hydrodynamic radius $\left(R_{\mathrm{h}}\right)$ distributions were detected, and the average $R_{\mathrm{h}}$ varies in the range of $10-500 \mathrm{~nm}$. This indicates that there exist large aggregates in the surfactant solution, which should be assigned to vesicles. ${ }^{21,77-79}$ The formation of these vesicles may be due to that there are four larger hydrophilic head groups, four hydroxyl groups in the spacer, and smaller counterions bound by these aggregates in comparison with traditional cationic surfactants. ${ }^{\mathbf{7 0 , 8 0}}$ It is clearly that these tetrameric surfactants in aqueous solution have a strong tendency to aggregate and form aggregates with large size distribution as hydrocarbon chain length of $4 \mathrm{C}_{n}$ tetraQ increases, due to the strong hydrophobic interaction among four alkyl chains..$^{21}$ However, these results are not completely accordance with those obtained from star-like cationic trimeric surfactants. ${ }^{39}$ And their results from DLS and Transmission

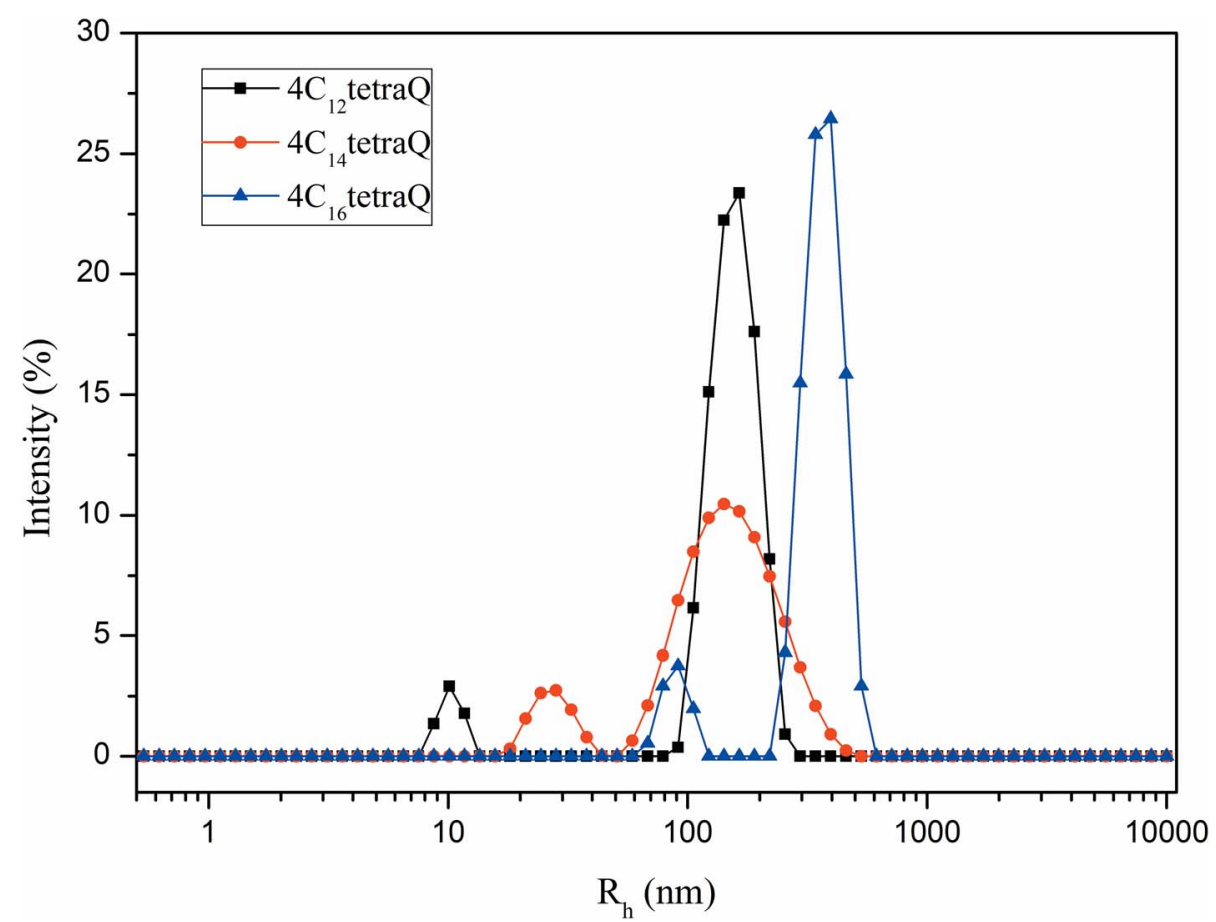

Fig. 5 The size distribution of aggregates of $4 C_{n}$ tetraQ at the concentration of 10 times of CMC. 


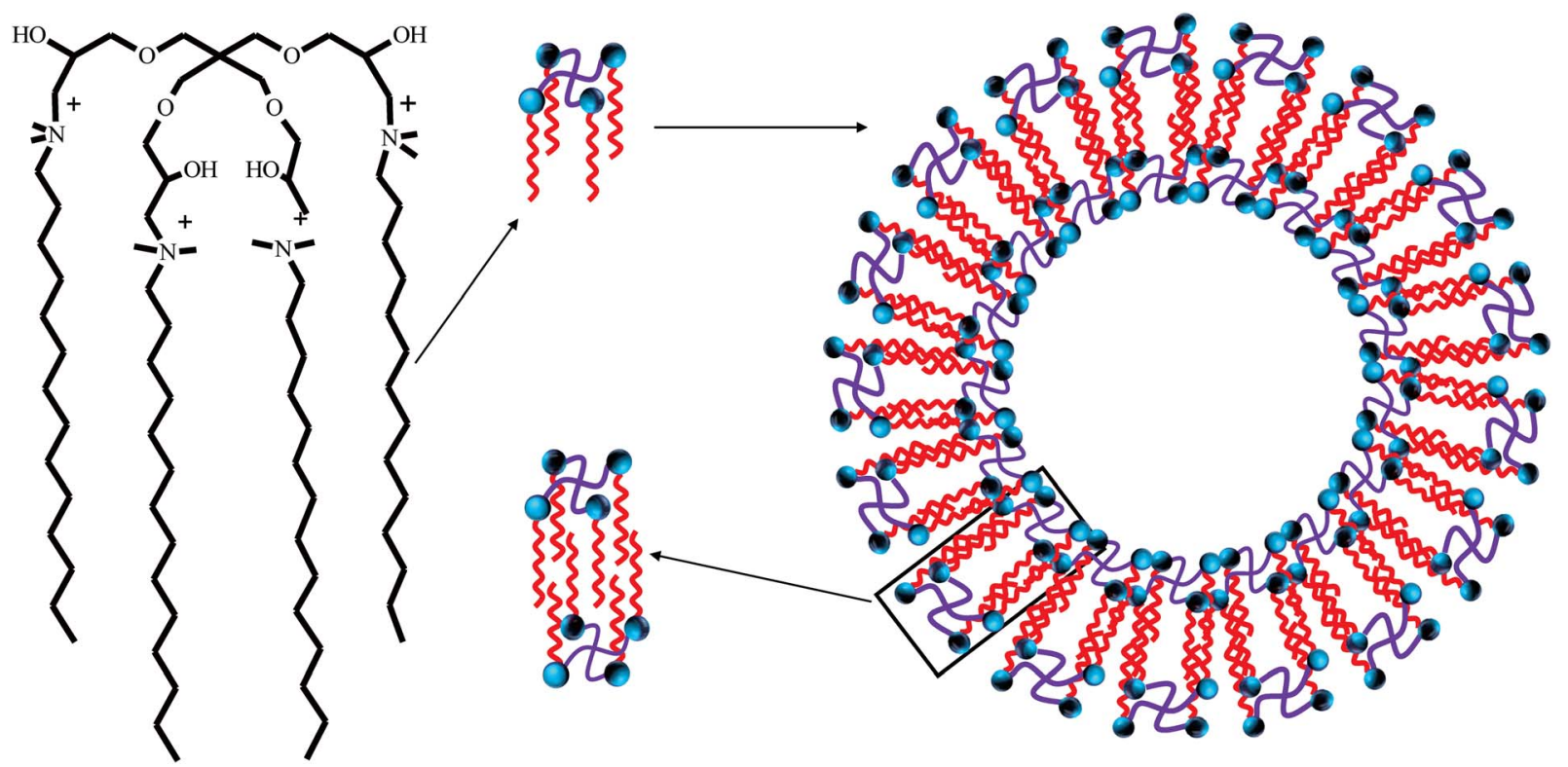

Fig. 6 The possible aggregate model of $4 C_{n}$ tetraQ in the aqueous solution.

Electron Microscopy (TEM) measurements show that there exist small globule micelles and large ellipsoidal vesicles, and that the numbers of large vesicles decrease with increasing alkyl chain length.

In addition, there is an exception that the $p$ value of $4 \mathrm{C}_{12^{-}}$ tetraQ (where $P=0.44$ ) is not incompletely accordance with the results from the DLS measurements, which may be due to that the calculated value of average parking area $\left(a_{0}\right)$ of polar head groups of $4 \mathrm{C}_{12}$ tetraQ is larger than its practical value. ${ }^{75}$ To explore arrangement of the alkyl chains in the vesicular region, the length ranges of hydrophobic chains $\left(R_{\max }\right.$ and $\left.R_{\min }\right)$ can be calculated by Tanford's equation.

For $4 \mathrm{C}_{n}$ tetraQ, the length of their alkyl chain fully extended is smaller than $R_{\min }$ or falls in between $R_{\max }$ and $R_{\min }$, which indicates that these tetrameric surfactant molecules present face-to-face attitude and easily interdigitate.$^{75}$ Thus, the bilayer thickness of vesicles is less than twice the length of the hydrophobic chain, and the possible aggregate model was given in Fig. 6 .

\section{Conclusions}

A series of dendritic cationic tetrameric surfactants were synthesized with raw materials that are commercially available. The synthesized surfactants have better surface activities than those of the corresponding monomeric and dimeric surfactants, and are more prone to self-assemble in the aqueous solution than adsorb at the air/solution surface. The thermodynamic parameters $\left(\Delta G_{\text {mic }}^{\mathrm{o}}, \Delta H_{\text {mic }}^{\mathrm{o}}, \Delta S_{\text {mic }}^{\mathrm{o}}, \Delta G_{\text {ads }}^{\mathrm{o}}\right)$ obtained from electrical conductivity measurements show that both processes of adsorption and micellization of $4 \mathrm{C}_{n}$ tetraQ are spontaneous, and that the micellization processes of these surfactants are entropy-driven. Both adsorption and micellization of $4 \mathrm{C}_{n}$ tetraQ are inclined to occur with the increase of alkyl chain length or temperature. The DLS measurements reflect that there exist large aggregates, assigned to vesicles, at the concentration of 10 times of the CMC, which is incompletely accordance with the critical packing parameters $(P)$ obtained by Tanford's expression. Given few reports on oligomeric surfactants, the paper helps to understand physicochemical properties of tetrameric surfactants with dendritic structure, aid the design synthesis of novel oligomeric surfactants, and study their structure-performance relationship.

\section{Conflicts of interest}

There are no conflicts to declare.

\section{Acknowledgements}

We thank the financial support from the National Natural Science Foundation of China (Grant No. 51674085). The authors acknowledge the assistance of Northwest University in performing elemental analysis experiments.

\section{References}

1 R. Domínguez, A. Rodríguez, A. Maestre, I. Robina and M. L. Moyá, J. Colloid Interface Sci., 2012, 386, 228-239.

2 L. Y. Wang, Y. Zhang, L. M. Ding, J. Liu, B. Zhao, Q. G. Deng and T. Yan, RSC Adv., 2015, 5, 74764-74773.

3 A. K. Tiwari, Sonu and S. K. Saha, J. Chem. Thermodyn., 2014, 70, 24-32.

4 M. A. Migahed, M. M. Shaban, A. A. Fadd, T. A. Ali and N. A. Negm, RSC Adv., 2015, 5, 104480-104492.

5 T. Zhang, X. Cao, X. Wang and C. Song, J. Mol. Liq., 2017, 230, 505-510.

6 T. Jiao, X. Liu, X. Wang, Y. Wang and J. Niu, Colloids Surf., A, 2016, 498, 30-41.

7 A. Bhadani and S. Singh, Langmuir, 2011, 27, 14033-14044. 
8 L. Zhou, X. Jiang, Y. Li, Z. Chen and X. Hu, Langmuir, 2007, 23, 11404-11408.

9 H. Wang, T. Kaur, N. Tavakoli, J. Joseph and S. Wettig, Phys. Chem. Chem. Phys., 2013, 15, 20510-20516.

10 K. Wang, D. S. Guo, X. Wang and Y. Liu, ACS Nano, 2011, 5, 2880-2894.

11 Q. Chen, Y. Sakamoto, O. Terasaki and S. Che, Microporous Mesoporous Mater., 2007, 105, 24-33.

12 P. V. D. Voort, M. Mathieu, A. F. Mees and E. F. Vansant, J. Phys. Chem. B, 1998, 102, 8847-8851.

13 V. Branzoi, F. Branzoi and M. Baibarac, Mater. Chem. Phys., 2000, 65, 288-297.

14 W. Li, H. Chen, Z. He, C. Han, S. L. Liu and Y. Li, LWT-Food Sci. Technol., 2015, 62, 39-47.

15 L. Wattebled, A. Laschewsky, A. Moussa and J. Habib-Jiwan, Langmuir, 2006, 22, 2551-2557.

16 Y. B. Hou, M. W. Cao, M. L. Deng and Y. L. Wang, Langmuir, 2008, 24, 10572-10574.

17 Y. B. Hou, Y. C. Han, M. L. Deng and J. F. Xiang, Langmuir, 2010, 26, 28-33.

18 X. Li, F. L. Xing, Q. Xu, X. L. Sun, Y. P. Wang, L. Y. Wang and P. L. Wang, J. Surfactants Deterg., 2016, 19, 129-135.

19 R. L. Qi, M. N. Wang, L. Y. Zhu, Z. Liu and Y. L. Wang, Langmuir, 2017, 33, 7271-7280.

20 N. Sun, L. Shi, F. Lu, S. T. Xie, P. P. Sun and L. Q. Zheng, Langmuir, 2015, 31, 2281-2287.

21 I. Martin, B. Veronique, A. C. Olivier and R. Zana, Langmuir, 2000, 16, 141-148.

22 T. Yoshimura, H. Yoshida, A. Ohno and K. Esumi, J. Colloid Interface Sci., 2003, 267(1), 167-172.

23 A. Laschewsky, L. Wattebled, M. J. L. Arotçaréna, J. L. HabibJiwan and R. H. Rakotoaly, Langmuir, 2005, 21, 7170-7179.

24 T. Yoshimura and K. Esumi, Langmuir, 2003, 19, 3535-3538.

25 M. C. Murguía, M. I. Cabrera, J. F. Guastavino and R. J. Grau, Colloids Surf., A, 2005, 262, 1-7.

26 M. C. Murguía and R. J. Grau, Synlett, 2001, 8, 1229-1232.

27 D. H. McCullough, V. Janout, J. W. Li, J. T. Hsu, Q. Truong, E. Wilusz and S. L. Regen, J. Am. Chem. Soc., 2004, 126, 9916-9917.

28 F. M. Menger and V. A. Migulin, J. Org. Chem., 1999, 64, 8916-8921.

29 Y. Sumida, T. Oki, A. Masuyama, H. Maekawa, M. Nishiura, T. Kida, Y. Nakatsuji, I. Ikeda and M. Nojima, Langmuir, 1998, 14, 7450-7455.

30 T. Yoshimura, N. Kimura, E. Onitsuka, H. Shosenji and K. Esumi, J. Surfactants Deterg., 2004, 7, 67-74.

31 T. Yoshimura, T. Kusano, H. Iwase, M. Shibayama, T. Ogawa and H. Kurata, Langmuir, 2012, 28, 9322-9331.

32 A. Uner, E. Doganci, M. A. Tasdelen, F. Yilmaz and A. G. Gürek, Polym. Int., 2017, 66, 1610-1616.

33 Z. W. Li, Z. Y. Shi, S. L. Zhao, S. Yin, G. R. Tan, B. Jing and Y. B. Tan, J. Surfactants Deterg., 2016, 19, 1107-1120.

34 C. X. Wu, Y. B. Hou, M. L. Deng, X. Huang, D. F. Yu, J. F. Xiang, Y. Liu, Z. B. Li and Y. L. Wang, Langmuir, 2010, 26(11), 7922-7927.

35 Y. X. Fan, Y. B. Hou, J. F. Xiang, D. F. Yu, C. X. Wu, M. Z. Tian, Y. C. Han and Y. L. Wang, Langmuir, 2011, 27, 10570-10579.
36 D. Wang, M. W. Cao, Y. Chen, Z. Liu, C. X. Wu, H. Xu, S. Wang and Y. L. Wang, ACS Appl. Mater. Interfaces, 2016, 8, 30811-30823.

37 N. Kampf, C. X. Wu, Y. L. Wang and J. Klein, Langmuir, 2016, 32, 11754-11762.

38 Y. C. Xie, J. Li, T. Sun, Y. Han, G. M. Qu and R. X. Niu, J. Dispersion Sci. Technol., 2017, 39, 1153-1159.

39 X. G. Liu, X. J. Xing and Z. N. Gao, Colloids Surf., A, 2014, 457, $374-381$.

40 E. M. Kandeel, J. Dispersion Sci. Technol., 2013, 33, 949-954.

41 E. Alami, G. Beinert, P. Marie and R. Zana, Langmuir, 1993, 9, 1465-1467.

42 Q. Zhang, Z. N. Gao, F. Xu, S. X. Tai, X. G. Liu, S. B. Mo and F. Niu, Langmuir, 2012, 28, 11979-11987.

43 M. Q. Ao, G. Y. Xu, Y. Y. Zhu and Y. Bai, J. Colloid Interface Sci., 2008, 326, 490-495.

44 L. H. Zhuang, K. H. Yu, G. W. Wang and C. Yao, J. Colloid Interface Sci., 2013, 408, 94-100.

45 M. Zhou, Z. Huang, S. Yu, Y. Yang, Y. S. Huang, D. Qiu and J. Z. Zhao, Tenside, Surfactants, Deterg., 2016, 53, 134-139.

46 O. Kaczerewska, B. Brycki, I. Ribosa, F. Comelles and M. T. Garcia, J. Ind. Eng. Chem., 2018, 59, 141-148.

47 M. U. H. Mir, N. Maurya, I. Beg, A. B. Khan and R. Patel, Colloids Surf., A, 2016, 507, 36-45.

48 I. Aiad, M. A. Riya, S. M. Tawfik and M. A. Abousehly, Egypt. J. Pet., 2016, 25, 299-307.

49 M. Abo-Riya, A. Tantawy and W. El-Dougdoug, J. Mol. Liq., 2016, 221, 642-650.

50 K. Taleb, M. Mohamed-Benkada, N. Benhamed, S. SaidiBesbes, Y. Grohens and A. Derdour, J. Mol. Liq., 2017, 241, 81-90.

51 J. W. Guo, X. Zhong, H. Zhu and L. J. Feng, Chin. Chem. Lett., 2o13, 23, 653-656.

52 A. Sokołowski, A. Bieniecki, K. A. Wilk and B. Burczyk, Colloids Surf., A, 1995, 98, 73-82.

53 C. L. Dai, S. S. Fang, M. Hu, X. J. He, M. W. Zhao, X. P. Wu, S. Yang and Y. N. Wu, J. Ind. Eng. Chem., 2017, 54, 226-233.

54 J. Darija, H. Ivan and F. C. Nada, Colloids Surf., A, 2010, 368, 119-128.

55 P. Patial, A. Shaheen and I. Ahmad, J. Surfactants Deterg., 2014, 17, 253-260.

56 X. Zhong, J. Guo, L. Feng, X. Xu and D. Zhu, Colloids Surf., A, 2014, 441, 572-580.

57 L. F. Zhi, Q. X. Li, Y. L. Li and Y. Q. Sun, Colloids Surf., A, 2014, 456, 231-237.

58 R. Kamboj, S. Singh, A. Bhadani, H. Kataria and G. Kaur, Langmuir, 2012, 28, 11969-11978.

59 G. H. Sayed, F. M. Ghuiba, M. I. Abdou, E. A. A. Badr, S. M. Tawfik and N. A. M. Negm, J. Surfactants Deterg., 2012, 15, 735-743.

60 N. Azum, M. A. Rub, A. M. Asiri and W. A. Bawazeer, Colloids Surf., A, 2017, 522, 183-192.

61 I. Aiad, M. M. E. Sukkary, E. A. Soliman, M. Y. E. Awady and S. M. Shaban, J. Ind. Eng. Chem., 2014, 20, 1633-1640.

62 S. M. Shaban, A. S. Foud, M. A. Elmorsi, T. Fayed and O. Azazy, J. Mol. Liq., 2016, 216, 284-292. 
63 S. M. Shaban, A. S. Foud, S. M. Rashwan, H. E. Ibrahim and M. F. El-Bhrawy, J. Mol. Liq., 2016, 221, 224-234.

64 D. Q. Xu, X. Y. Ni, C. Y. Zhang, J. Mao and C. C. Song, J. Mol. Liq., 2017, 240, 542-548.

65 G. Y. Liu, D. M. Gu, H. Y. Liu, W. Ding, H. X. Luan and Y. M. Lou, J. Colloid Interface Sci., 2012, 375, 148-153.

66 Y. Bao, J. Guo, J. Ma, M. Li and X. L. Li, J. Mol. Liq., 2017, 242, 8-15.

67 G. B. Ray, I. Chakraborty and S. P. Moulik, Colloid Interface Sci., 2006, 294, 248-254.

68 N. Azum, M. A. Rub, A. M. Asiri, K. A. Alamry and H. M. Marwani, J. Dispersion Sci. Technol., 2014, 35, 358-363.

69 K. Esumi, K. Taguma and Y. Koide, Langmuir, 1996, 12, 4039-4041.

70 V. Chauhan, S. Singh, R. Mishra and G. Kaur, J. Colloid Interface Sci., 2014, 436, 122-131.

71 A. Rodríguez, M. M. Graciani and M. L. Moya, Langmuir, 2008, 24, 12785-12792.
72 R. Zana and H. Lévy, Colloids Surf., A, 1997, 127, 229-232.

73 C. H. Hsu, S. M. Shau, R. J. Jeng, H. C. Chiu, S. H. A. Dai, E. D. Conted and S. Y. Suen, Microchem. J., 2013, 110, 48-53.

74 J. Aguiar, P. Carpena, J. A. Molina-Bolívar and C. C. Ruiz, J. Colloid Interface Sci., 2003, 258, 116-122.

75 B. Li, Q. Zhang, Y. Xia and Z. N. Gao, Colloids Surf., A, 2015, 470, 211-217.

76 K. Maiti, S. C. Bhattachary, S. P. Moulik and A. K. Panda, Colloids Surf., A, 2010, 355, 88-98.

77 G. Y. Wang, Q. W. Yin, J. X. Shen, Y. Y. Bai, X. Y. Ma, Z. P. Du and W. X. Wang, J. Mol. Liq., 2017, 234, 142-148.

78 G. Wang, P. Li, Z. Du, W. Wang and G. Li, Langmuir, 2015, 31, 8235-8242.

79 Z. T. Liu, Y. F. Ge, Q. Zhang, X. Gao, X. Cai, M. Y. Chen and X. C. Yu, J. Surfactants Deterg., 2017, 20, 765-775.

80 B. Dong, X. Y. Zhao, L. Q. Zheng, J. Zhang, N. Li and T. Inoue, Colloids Surf., A, 2008, 317, 666-672. 